\title{
Social capital and knowledge sharing in academic research teams
}

\section{Paola García-Sánchez}

$@$ SAGE

Universidad de Las Palmas de Gran Canaria, Spain

\section{Nieves L. Díaz-Díaz}

Universidad de Las Palmas de Gran Canaria, Spain

\section{Petra De Saá-Pérez}

Universidad de Las Palmas de Gran Canaria, Spain

\begin{abstract}
The purpose of this article is to analyse the role of social capital within academic research teams and its influence on knowledge sharing. An empirical study was carried out with 87 academic research teams at a Spanish university. The results show that internal ties have a positive effect on trust. Moreover, the results also reflect that both dimensions of social capital (internal ties and trust) have a positive and significant effect on research teams' knowledge sharing. Therefore, the findings reveal that the network's structure has a positive influence on the quality of relationships among academic researchers that favour knowledge sharing.
\end{abstract}

\section{Points for practitioners}

The results provide universities' managers with a better understanding of internal social capital in academic research teams, which has important implications for researchers' willingness to collaborate and share knowledge. Public university managers may use strategies to improve interdependence among research team members, favouring social relations among researchers. Thus, public universities should enhance research teams with stronger ties and high levels of trust that increase knowledge sharing.

\section{Keywords}

internal ties, knowledge management, knowledge sharing, public universities, research teams, trust

\section{Corresponding author:}

Paola García-Sánchez, Universidad de Las Palmas de Gran Canaria, Campus de Tafira s/n, 35017, Las Palmas de Gran Canaria, 35003, Spain.

Email: paola.garcia102@alu.ulpgc.es 


\section{Introduction}

In the past two decades, competition among universities has become globalized, and higher education systems are under intense pressure to improve their services. Universities have to respond to many types of pressure, such as decreasing governmental financial assistance and new demands from social actors, among others (Kim and Bak, 2016; Salaran, 2010). These challenges require universities to expand their activities related to knowledge management. In this regard, a main goal of public universities is the creation and transfer of knowledge through one of their most important intangible assets: researchers (Ramírez et al., 2015). Academics at public universities are encouraged to generate knowledge that is relevant and useful to industry, but reputation, incentive schemes and professional career progression are also closely linked to scientific excellence (Fullwood et al., 2013). In this context, the development of new scientific knowledge has evolved as it is no longer based on individual work, but rather based on collaboration and cooperation among researchers (Gonzalez-Brambila, 2014; Stvilia et al., 2011). These relationships allow academic researchers to learn from each other, and they lead to new scientific findings. Consequently, creating a research team becomes an important challenge because the generation of new knowledge is a result not only of the work of individual researchers, but also of the relationships established among them (Pezzoni et al., 2012; Widén-Wulff and Ginman, 2004).

The knowledge developed by a researcher comes from the scientific community and returns there for discussion, validation and the broadening of the scientific field (Bolisani and Scarso, 2014). Research teams provide a way to gather knowledge in the academic context in order to come up with new ideas and solutions (Bakker et al., 2006). However, academics who form part of research teams within the structure of public universities do not seem to be enough for knowledge transfer. Social relationships shared by researchers within these teams are necessary to promote the commitment, mutual understanding, identity, trust and cohesion that favour knowledge management (Zboralski, 2009).

Within this context, the concept of social capital can be useful in explaining knowledge sharing (Chung and Jackson, 2013). For academics, sharing individual knowledge means that they are exposed to criticism and debate from other members of the research team in order to incorporate new knowledge and shape the initial idea (Wang et al., 2006). For this reason, 'it is important to realize that knowledge needs to be nurtured, supported, enhanced, and cared for' (WidénWulff and Ginman, 2004: 449). Therefore, it is necessary to expose individual work to a social process, and these social processes must be managed to encourage knowledge sharing. This situation makes universities more aware of the need to establish the correct mechanisms to foster the exchange of flows of knowledge. It is vital to understand the structure and content of the relationships among the members of the research team.

Although cultivating effective work relationships has been studied extensively in the literature of knowledge management (for a review, see Carpenter et al., 2012; Phelps et al., 2012), some authors recognize that 'employees are not always 
competent or motivated to share their knowledge with others, have trouble understanding each other or differ in how they make sense of situations' (Van Dijk et al., 2016: 327). Thus, the purpose of this article is to extend the literature about the way in which social capital contributes to knowledge sharing ( $\mathrm{Hu}$ and Randel, 2014; Wei-Li and Yi-Chih, 2016). Particularly, the objective of the study is to analyse how the internal ties and trust among the members of research teams contribute to knowledge sharing in the academic context, highlighting the importance of encouraging strong ties among the members of a research team in order to promote trust and share knowledge appropriately. Therefore, our article contributes to the literature on social capital and knowledge sharing by revealing that structural and relational dimensions of researchers' social capital are interconnected, not isolated. The value of the strong ties of researchers is completely realized if team members trust one another and are thereby willing to share knowledge (Karahannan and Preston, 2013). Although most previous studies have focused on the individual level, our study considers that in the Spanish academic context, teams are the basic unit of research in many scientific disciplines (Olmos-Peñuela et al., 2014).

The article is structured in five sections. After an introduction, the next section develops the theoretical framework and formulates the hypotheses. The third section describes the methodological aspects. The results of the empirical analysis are explained in the fourth section, whereas the conclusions are presented in the fifth, along with the implications and future lines of research.

\section{Theory and hypotheses}

Social capital can be defined 'as the sum of the actual and potential resources embedded within, available through, and derived from the network of relationships possessed by an individual or social unit' (Nahapiet and Ghoshal, 1998: 243). Thus, it is the degree to which the contacts in a network have valuable resources that can be reached through their relationships, as well as the network's ability to transmit and make the resources available to all members (Inkpen and Tsang, 2005; Nahapiet and Ghoshal, 1998; Pil and Leana, 2009).

In the academic context, research team members are considered to be a community of researchers who work together in approaching and developing research activities and sharing material and financial resources. They 'have to invest time and effort for generating, growing, and sustaining social relationships' (Maurer et al., 2011: 160) in order to encourage the flow of knowledge among team members with different types of specialized and diverse expertise (Grant, 1996). This bidirectional process where team members exchange organizationrelated information, ideas, suggestions and expertise with each other is defined as knowledge sharing. This process is a critical stage in knowledge transfer, which involves knowledge donation and knowledge collection (Tangaraja et al., 2016). Therefore, knowledge sharing requires team members to surrender their knowledge and, at the same time, to be able to obtain knowledge from their colleagues for its modification and reuse (Chen and Hung, 2010). 
Social capital is a multidimensional concept (Zheng, 2010) that includes the description of the structure and content of social relations (Granovetter, 1973). The structure comprises aspects related to the setting and properties of the network, whereas the relational dimension encompasses aspects related to the content and quality of the relationships developed among the members through their interaction. As Zheng (2010) points out, the former captures the physical setting of relationships, whereas the latter comprises their substance, and one cannot be understood without the other.

The ties created within a research team are closely linked to the time, intensity and reciprocity in a relationship among researchers (Granovetter, 1973; Levin et al., 2016; Maurer et al., 2011). A researcher's ties are stronger when the intensity of the relationship with his/her contacts increases (Jacob and Meek, 2013). Different types of interaction affect the quantity and quality of the knowledge shared (Chiu et al., 2006). Knowledge sharing is the result of the analysis of benefits and costs, so that researchers "will not share unless they perceive the benefits of sharing, such as reciprocal benefits, rewards, and stronger interpersonal ties' (Chen and Hsieh, 2015: 814). Strong ties favour the exchange process and encourage the context where knowledge is shared (Chang and Chuang, 2011). The social structure in which a researcher is located is a source of social capital as an opportunity for knowledge sharing. According to Levin et al. (2016: 419) 'ties' strength also makes people more willing to share what they know and to listen to and absorb what the other person has to say'.

The content and quality of relationships is part of the relational dimension of social capital, where mutual trust is an important component that has received considerable attention in previous studies (Zheng, 2010). Abrams et al. (2003: 65) view interpersonal trust as a central characteristic of relationships that promotes effective knowledge creation'. Trust can be understood as an expectation about the future conduct of another member, having confidence in their actions and recognizing that the vulnerability will not be exploited if opportunistic behaviour arises (Barczak et al., 2010). Moreover, trust in contexts of knowledge sharing, such as research teams, includes affective and cognitive aspects (Holste and Fields, 2010; McAllister, 1995). Trust within academic research teams comes with the concern members express about each other's interests and objectives (affective), as well as trust in the other researchers based on their reliability and experience (cognitive).

It can be stated that the structure of the network influences the development of the content of relationships (Nahapiet and Ghoshal, 1998). Strong internal ties among researchers become an important aspect in improving the content and resources stemming from their relationships with other researchers. As a result of the intensity of relationships among researchers, a sense of belonging, mutual understanding and learning is developed through observation and interaction among the members, as well as the creation of shared languages and codes (Holste and Fields, 2010). In this regard, Zboralski (2009: 94) states that 'the frequency of interaction influences the development of trust between community members. Similarly, the frequency of interaction influences the feeling of sympathy 
between members of a team'. In addition, frequent and close interaction may stimulate trust (Liao and Welsch, 2003; Tsai and Ghoshal, 1998), allowing researchers to know and perceive each other as trustworthy. Thus, strong internal ties reduce opportunism and are beneficial to all team members in sharing knowledge.

Knowledge sharing requires researchers to become involved in joint discussions and the exchange of ideas (Han et al., 2014). If there is more interaction among the research team members and their ties are more direct, they will be more willing to share their knowledge and stay in contact over time (Chang and Chuang, 2011; Wang and Noe, 2010). Strong internal ties increase the likelihood that researchers within a team will share and use information from other members and improve knowledge (Hentonnen et al., 2014). The previous arguments state that researchers' stronger ties will facilitate the transfer of knowledge and affect the quantity and quality of knowledge sharing in research teams (Chiu et al., 2006; Wang and Noe, 2010). In a trusting environment, researchers feel less vulnerable, and the motivation to share knowledge with the other team members increases. They become more tolerant about dissimilar ideas and, in turn, more open to the possibility of discovering new ideas (Abrams et al., 2003; Barczak et al., 2010; Holste and Fields, 2010). As Li et al. (2013: 1517) state: 'when two authors trust each other, they are more willing to collaborate and share resources without worrying that they will be taken advantage of by their counterpart'. Moreover, trust gives team members more freedom to generate ideas, and it can foster creativity through interactions among researchers on the team. Team members share knowledge because their team 'can increase its chance to make contact with knowledge sources by selecting members who have good interpersonal relationships with people within and outside the organisation' (Chuang et al., 2016: 528).

In summary, internal ties among the members of a research team promote mutual trust. Moreover, both dimensions of social capital are expected to have a positive effect on the willingness to share knowledge. Based on these considerations, the following hypotheses are proposed:

H1: Internal ties have a positive effect on trust among academic research team members.

$\mathrm{H}$ 2: Social capital within academic research teams has a positive effect on knowledge sharing.

H2a: Internal ties within academic research teams have a positive effect on knowledge sharing.

$\mathrm{H} 2 \mathrm{~b}$ : Trust among academic research team members has a positive effect on knowledge sharing.

\section{Methodology}

\section{Sample}

With the aim of testing the previously proposed hypotheses, an empirical study was conducted at a Spanish university, taking into account all the research groups (157). 
Public universities often highlight differences in their promotion practices, training and other institutional characteristics. To avoid these interferences, this article focuses on a single public university.

Previous literature based on bibliometric techniques has analysed the researchers' social capital dimensions based on the frequency of their co-authorship, and, thus, research teams are not necessarily the units of study (e.g. Gonzalez-Brambila, 2014; Pezzoni et al., 2012). Therefore, researchers who do not publish are omitted. Other studies define teams on the basis of administrative agreements that include all members, whether they publish or not (Perianes-Rodríguez et al., 2010). This article considers the second definition. At Spanish universities, the research teams are considered as a community of researchers who work together in approaching and developing research activities and sharing material and financial resources, and they are organized under the formal structure of the institution where their activity takes place.

A survey was sent to all the researchers who were members of research teams through institutional mail. The response rate was $75.16 \%$, based on the number of research groups (responses from 118 teams). As the research team is considered the unit of analysis in this study, a requirement was that at least two members of the team had to respond to the survey in order to retain data for that group. As a result, the final sample included 283 researchers belonging to 87 research groups in five different fields of knowledge.

With regard to the answers obtained for each knowledge area, it can be noted that $26.44 \%$ of the academic research groups belong to Social and Law Sciences, followed by $23 \%$ in Arts and Humanities, and $18.39 \%$ in Health Sciences. Finally, $16 \%$ of the groups belong to the knowledge area of Science, and the same percentage of the groups belong to the area of Engineering and Architecture.

\section{Variables}

Knowledge sharing. The knowledge-sharing variable was measured with a fiveitem scale, adapted from Chow and Chan (2008) and Liu et al. (2011), in which each member of a research team valued the level of knowledge shared among them during the period of the study. A seven-point scale was used, where 1 represents 'strongly disagree' and 7 represents 'strongly agree'.

Items of the scale are in Appendix 1. An example is: 'Members of my research team share with each other their research results'. In order to analyse the convergent validity and reliability of the constructs, confirmatory factor analysis was conducted to test the unidimensionality of the scale. Factor loadings were above 0.7 and showed a Cronbach's alpha value of 0.957 , demonstrating the validity and reliability of the scale.

Internal ties. The internal ties are measured by the number of team members with whom a researcher usually works, in relation to the theoretical maximum total 
number of researchers in the team. Thus, we asked each researcher how many members of the research group usually worked with them; then, we divided that number by the size of his/her research team. Therefore, if all the team's members have connections with each other, the ties variable takes the value of 1 , and if there are no connections, it is 0 . After that, this variable is calculated for each research team as the average of the researchers' ties. Previous studies considered similar measures of internal ties (e.g. Chung and Jackson, 2013; Hentonnen et al., 2014; Maurer et al., 2011; Wong, 2008).

Trust. This variable was measured with a scale adapted from Chow and Chan (2008), in which researchers valued the trust among the research team members during the period of the study. A seven-point Likert-type scale was used, where 1 represents 'strongly disagree' and 7 represents 'strongly agree'. A sample item is 'Members of my research team always rely on other members to offer their help when necessary'. In order to analyse the convergent validity and reliability of the constructs, a confirmatory factor analysis was conducted to test the unidimensionality, with a Cronbach's alpha value of 0.961 (see Appendix 1).

Control variables. Additional variables were included to control for the influence of other characteristics related to researchers and their teams that can also affect the knowledge shared. The control variables included in this study are: Knowledge area, considered through five dummy variables that adopt the value of 1 if the team belongs to a specific area - Arts and Humanities, Social and Law Sciences, Sciences, Health Sciences, and Engineering and Architecture; Team size, measured by the average number of members on each academic research team during the period of the study; and Gender, introduced as the percentage of women belonging to the research team. In addition, the percentage of members holding a $\mathrm{PhD}(\mathrm{PhD}$ members) in each team was included, as well as their seniority as a $\mathrm{PhD}$ (Years holding a PhD), measured as the number of years since each researcher obtained his/her $\mathrm{PhD}$ and the year of the study. The percentage of non-civil servant members (NonCivilServant) in each team is also included.

\section{Econometric specification}

In this study, simultaneous equation models were estimated using three-stage least squares (3SLS). In order to contrast the hypotheses about the influence of internal ties and trust on knowledge sharing, as well as the effect of internal ties on the research team's trust, a system of two simultaneous equations was specified:

$$
\begin{aligned}
\text { Trust }= & \beta_{0}+\beta_{1} \text { Internal ties }_{\mathrm{i}}+\beta_{2} \text { PhD members } \\
& +\beta_{3} \text { Team size }_{\mathrm{i}}+\beta_{4} \text { Years_of_PhD }_{\mathrm{i}} \\
& +\beta_{5} \text { Gender }_{\mathrm{i}}+\varepsilon_{\mathrm{i}} \\
\mathrm{i}=1, \ldots, 87 &
\end{aligned}
$$


Knowledge sharing $=\beta_{0}+\beta_{1}$ Internal ties $_{\mathrm{i}}+\beta_{2}$ Trust $_{\mathrm{i}}+\beta_{3}$ Knowledge area $_{\mathrm{i}}$ $+\beta_{4}$ Team size $_{\mathrm{i}}+\beta_{5}$ Gender $_{\mathrm{i}}+\beta_{6}$ NonCivilServant $_{\mathrm{i}}+\varepsilon_{\mathrm{i}}$

$$
\mathrm{i}=1, \ldots, 87
$$

The first equation (1) considers the endogenous variable (trust) as the dependent variable, and it includes a set of control variables. Internal ties are also the key explanatory variable of interest. The second equation (2) is related to the research team's knowledge sharing and includes the effect of one endogenous variable (trust). In this equation, internal ties are the second key explanatory variable of interest while controlling for several characteristics that affect research teams' knowledge sharing.

The system of equations presents an endogenous variable (trust). The estimation by Ordinary Least Squares (OLS) could obtain biased or inconsistent estimators. Consequently, in order to test the hypotheses proposed, the models were estimated to apply the simultaneous equations approach using 3SLS. Model estimation is carried out with the econometric program STATA 11.

\section{Results}

\section{Descriptive statistics and correlation matrix}

Table 1 summarizes the descriptive statistics for the academic research teams. These teams are made up of an average of 11 members. Regarding gender composition, $40.54 \%$ of team members are women, and $45.72 \%$ of the members are non-civil servants. Moreover, on average, $68.79 \%$ of the team members hold a $\mathrm{PhD}$, with a seniority of 16 years.

The descriptive statistics for the knowledge sharing and social capital dimensions are presented in Table 2. There are significant differences between the research teams with strong and weak internal ties. The data reveal that in academic research teams with strong internal ties, trust among the members is above average. Regarding knowledge sharing within research teams, there are significant

Table I. Descriptive statistics of academic research teams.

\begin{tabular}{|c|c|c|c|c|c|}
\hline Variables & Mean & S.D. & $\begin{array}{l}\text { Ist } \\
\text { quartile }\end{array}$ & Median & $\begin{array}{l}\text { 3rd } \\
\text { quartile }\end{array}$ \\
\hline Team size & 11.269 & 7.976 & 6.60 & 10 & 13.20 \\
\hline Gender & 0.4054 & 0.239 & $0.24 I$ & 36.66 & 0.578 \\
\hline NonCivilServant & 0.4572 & 0.177 & 0.330 & 0.490 & 0.580 \\
\hline $\mathrm{PhD}$ members & 0.6879 & 0.204 & 0.538 & 0.667 & 0.857 \\
\hline Years of PhD & 16.050 & 4.898 & 13.125 & 16.00 & 19.33 \\
\hline
\end{tabular}


Table 2. Social capital and knowledge sharing in academic research teams.

Descriptive statistics of social capital and knowledge sharing

\begin{tabular}{lcccrr}
\hline & & & Ist & 3rd \\
& Mean & S.D. & quartile & Median & quartile \\
\hline Internal ties & 0.492 & 0.231 & 0.322 & 0.500 & 0.634 \\
Trust & 0.067 & 0.700 & -0.343 & 0.178 & 0.546 \\
Knowledge sharing & 0.060 & 0.707 & -0.405 & 0.143 & 0.635 \\
Internal ties and trust & & & & & \\
\hline
\end{tabular}

Trust

\begin{tabular}{lllllrl}
\hline Internal ties & Strong & 0.315 & 0.696 & -0.127 & 0.495 & 0.900 \\
& Weak & -0.198 & 0.607 & -0.730 & -0.125 & 0.317 \\
& $t$ test & $-3.654^{* * * *}$ & & & &
\end{tabular}

Knowledge sharing according to social capital dimensions

\begin{tabular}{llllrrr}
\hline \multicolumn{6}{l}{ Knowledge sharing } \\
\hline \multirow{7}{*}{ Internal ties } & Strong & 0.336 & 0.712 & 0.003 & 0.460 & 0.897 \\
& Weak & -0.235 & 0.576 & -0.567 & -0.102 & 0.150 \\
\multirow{3}{*}{ Trust } & $t$ test & $-4.09^{* * * *}$ & & & & \\
& Strong & 0.518 & 0.465 & 0.235 & 0.572 & 0.897 \\
& Weak & -0.453 & 0.568 & -0.920 & -0.300 & -0.003 \\
& $t$ test & $-8.76^{* * * *}$ & & & & \\
\hline
\end{tabular}

Note: Significant to: ${ }^{*} p<0.01$.

Table 3. Descriptive statistics and correlation matrix.

\begin{tabular}{|c|c|c|c|c|c|c|c|c|c|c|}
\hline \multirow[b]{2}{*}{ Variables } & \multirow[b]{2}{*}{ Mean } & \multirow[b]{2}{*}{ S.D. } & \multicolumn{8}{|c|}{ Correlations } \\
\hline & & & I & 2 & 3 & 4 & 5 & 6 & 7 & 8 \\
\hline $\begin{array}{l}\text { I. Knowledge } \\
\text { sharing }\end{array}$ & 0.06 & 0.71 & I & & & & & & & \\
\hline 2. Trust & 0.07 & 0.70 & $0.87^{* * * k}$ & I & & & & & & \\
\hline 3. Internal ties & 0.49 & 0.23 & $0.56^{* * * *}$ & $0.48^{* * * *}$ & I & & & & & \\
\hline 4. Team size & 11.26 & 7.97 & -0.14 & -0.16 & $-0.43^{* * k * k}$ & I & & & & \\
\hline 5. Gender & 0.41 & 0.24 & -0.16 & -0.11 & 0.08 & $-0.19^{*}$ & I & & & \\
\hline 6. NonCivilServant & 0.46 & 0.18 & -0.12 & -0.13 & 0.03 & 0.08 & $0.36^{* * 1 k k}$ & I & & \\
\hline 7. PhD Memers & 0.69 & 0.20 & $-0.21^{* *}$ & $-0.23^{* *}$ & -0.10 & -0.17 & 0.05 & $-0.21^{* *}$ & 1 & \\
\hline 8. Years of $\mathrm{PhD}$ & 16.05 & 4.90 & 0.13 & -0.03 & $0.29^{* * *}$ & -0.01 & -0.15 & -0.03 & 0.10 & 1 \\
\hline
\end{tabular}

Note: Significant to: ${ }^{* * *} p<0.01 ;{ }^{*} p<0.05 ;{ }^{*} p<0.1$. 
differences when taking into account their internal ties. The data show that in research teams where internal ties are strong, knowledge sharing is higher than in teams with weaker internal ties. Finally, the data also show differences in the value of knowledge sharing within academic research teams where trust is stronger compared to teams where it is weaker. Thus, research teams with higher levels of trust share more knowledge. These preliminary results are consistent with the proposed hypotheses regarding the relevance of both dimensions of social capital in academic research teams.

As the correlation matrix shows (see Table 3), internal ties and trust have a positive and significant correlation with knowledge sharing. Moreover, internal ties also show a positive and significant correlation with trust. Finally, regarding the explanatory variables, there are no multicollinearity problems, as the VIF (Variance Inflation Factor) values are less than 5 in all cases, with a mean value of 1.67 .

\section{Effect of social capital on knowledge sharing in academic research teams}

Table 4 presents the results obtained from the 3SLS estimation to test the hypotheses related to the effect of social capital on knowledge sharing. The dependent variable in the first equation is trust, and the explanatory variables include internal ties and a set of control variables. In the second equation, the dependent variable is knowledge sharing, whereas the explanatory variables are the team's internal ties, trust and a set of control variables.

The results of equation 1 reveal that the internal ties of academic researchers have a positive and significant effect $(\beta=1.74 ; p<0.001)$ on the trust developed within the teams. Thus, the stronger the internal ties, the higher the level of trust developed within the team, supporting hypothesis H1. Moreover, the results of equation 2 show a positive and significant influence of internal ties on knowledge sharing within research teams $(\beta=1.05 ; p<0.001)$. These results support hypothesis $\mathrm{H} 2 \mathrm{a}$, showing that stronger internal ties within research teams increase the knowledge sharing among their members. Furthermore, the results also show that trust has a positive and significant effect on knowledge sharing $(\beta=0.54 ; p<0.001)$, supporting $\mathrm{H} 2 \mathrm{~b}$, which indicates the importance of trust among the research teams' members in increasing knowledge sharing within the team.

The results of the estimated model support the hypotheses related to the effect of research teams' social capital on knowledge sharing, highlighting the direct and indirect effect of internal ties. The findings suggest that stronger ties have two positive effects on knowledge sharing. First, researchers with strong ties within their teams share more knowledge than those without these ties. Second, researchers with strong ties promote trust in order to share knowledge appropriately. The study reveals the existence of a mediator effect of trust in such a way that research teams with strong ties among their members, producing high levels of trust, share more knowledge. 
Table 4. Effect of social capital on knowledge sharing in academic research teams.

Model: simultaneous equation system (3SLS)

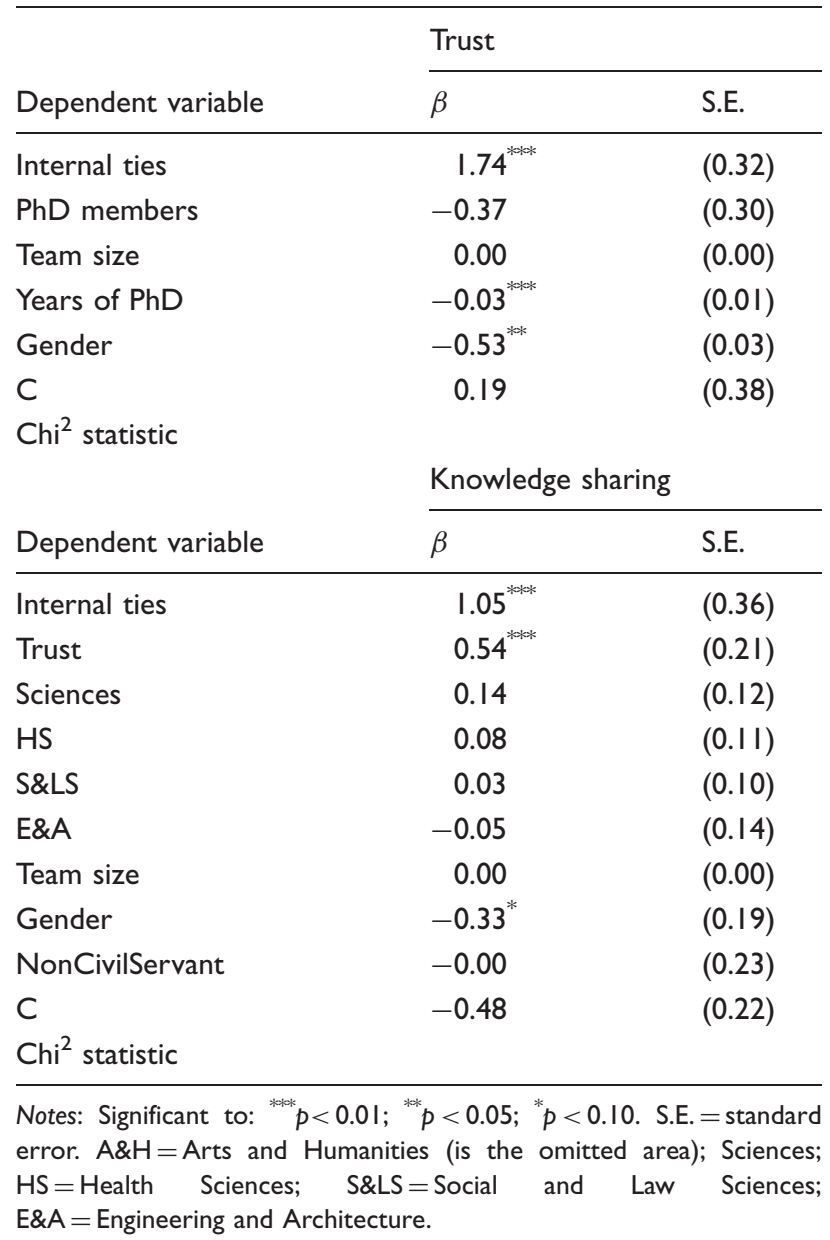

Regarding the control variables, the results show that gender has a negative effect on knowledge sharing. The results also show a negative and significant influence of gender on trust within the research team. In addition, there is a negative and significant relationship between $\mathrm{PhD}$ seniority and the trust of the research team.

\section{Conclusions}

Public universities play an important role in the creation and transfer of knowledge through the research carried out (Fullwood et al., 2013; Gonzalez-Brambila, 2014). 
The generation of scientific knowledge has evolved from individual work to a process based on collaboration among researchers (Stvilia et al., 2011). The decision to promote knowledge sharing by fostering the integration of academics in research teams becomes a key strategic question (Stvilia et al., 2011) that can help public universities to overcome the current competitive pressures (Kim and Bak, 2016; Salaran, 2010). Therefore, social relationships among researchers on these teams are necessary in order to promote the commitment, mutual understanding, identity, trust and cohesion that favour knowledge management (Zboralski, 2009).

Previous literature on social capital has paid more attention to scientific knowledge performance than to the analysis of the dimensions of social capital involved in knowledge sharing (Chung and Jackson, 2013; Han et al., 2014). In order to advance our understanding about the relationship between social capital and knowledge sharing, this article has examined how internal ties and trust favour knowledge sharing within academic research teams. The results reveal that the intensity of internal relations (strong ties) within research teams has a positive effect on creating a trusting environment. Moreover, both dimensions of social capital favour knowledge sharing in these teams. The findings reveal the existence of a mediator effect of trust, so that research teams with strong ties among their members that generate high levels of trust share more knowledge. These results highlight the need for organizations to design, support and manage this social process (Bolisani and Scarso, 2014), providing empirical evidence for the need to recognize and positively consider the nature of social relationships through researchers' involvement in activities where individual knowledge is available to their colleagues (Holste and Fields, 2010). These findings imply that investing in the creation of social capital in research teams eventually increases the knowledge shared within these teams. Social processes that depend on the organizational management of public universities have a positive influence on knowledge (Tian et al., 2009; Wang et al., 2006). Therefore, the improvement of the knowledge management process can also be beneficial to the economic system of a country, to the extent that scientific production is transferred to society.

According to the empirical results, we found that by creating better conditions for social interactions among members of research teams, a higher level of trust and team knowledge sharing can be promoted. The results clearly show that the stronger the ties are, the more likely it is for a research team to develop better team trust and a supportive climate for knowledge sharing. Public university managers may use the work structure design to improve interdependence among research team members. The results obtained also show that public universities should strengthen not only the importance of the structure of the network within research teams, but also trust, establishing a challenge for universities in terms of the management of social relations among researchers. In the academic context, because researchers have a priori individual interests that can reduce their effort to achieve team goals, it is important to promote social integration because knowledge sharing is not merely the sum of individual knowledge as independent pieces of a whole (Van den Hooff and Huysman, 2009). 
The present study contributes to using research teams as a unit of analysis because they are the basic unit of the Spanish research system (Olmos-Peñuela et al., 2014). The relevance of research teams is growing because they facilitate the university activities and almost the entire scientific community is organized into research teams (Ramos-Vielba et al., 2010). Previous studies define research teams as authors' networks obtained from the frequency of co-authorship, and, thus, they are not necessarily institutional units. Therefore, those researchers who do not publish are ignored, though they can share their knowledge with other researchers. However, in our article, research teams are taken as a community of researchers who work together along the lines of the formal structure of the institution where their research activity takes place. That is, the role of researchers that do not publish is also considered in order to share knowledge.

Although this article found several significant results, there are limitations that must be acknowledged and that suggest future research. Thus, it must be taken into account that this study has included existing ties among researchers from the same team. However, it is important to take into consideration the role of external contacts who provide diverse knowledge that favours new scientific findings. It is also important that we did not consider the reasons and motivations behind the research team's formation, which could be of interest in designing networks that promote knowledge sharing. In addition, to analyse the degree of knowledge shared within a team, future studies should consider measures that make it possible to differentiate between the quantity and quality of knowledge sharing, and include its effects on scientific productivity.

\section{Acknowledgements}

Thanks are due to the editor and two anonymous referees for their valuable assistance in improving the manuscript. Any errors or omissions remain the responsibility of the authors.

\section{Funding}

The authors are grateful for financial support received from the Research Project of the Ministry of Education and Science of Spain (ECO2010-201139 ECON).

\section{References}

Abrams LC, Cross R, Lesser E, et al. (2003) Nurturing interpersonal trust in knowledgesharing networks. The Academy of Management Executive 17(4): 64-77.

Bakker M, Leenders RTA, Gabbay SM, et al. (2006) Is trust really social capital? Knowledge sharing in product development projects. The Learning Organization 13: 594-605.

Barczak G, Lassk F and Mulki J (2010) Antecedents of team creativity: An examination of team emotional intelligence, team trust and collaborative culture. Creativity and Innovation Management 19: 332-345.

Bolisani E and Scarso E (2014) The place of communities of practice in knowledge management studies: A critical review. Journal of Knowledge Management 18: 366-381. 
Carpenter MA, Jiang H and Li M (2012) Social network research in organizational contexts: A systematic review of methodological issues and choices. Journal of Management 38: $1328-1361$.

Chang HH and Chuang SS (2011) Social capital and individual motivations on knowledge sharing: Participant involvement as a moderator. Information \& Management 48: 9-18.

Chen CA and Hsieh CW (2015) Knowledge sharing motivation in the public sector: The role of public service motivation. International Review of Administrative Sciences 81(4): 812-832.

Chen CJ and Hung SW (2010) To give or to receive? Factors influencing members' knowledge sharing and community promotion in professional virtual communities. Information \& Management 47(4): 226-236.

Chiu CM, Hsu MH and Wang ET (2006) Understanding knowledge sharing in virtual communities: An integration of social capital and social cognitive theories. Decision Support Systems 42(3): 1872-1888.

Chow W-S and Chan L-S (2008) Social network, social trust and shared goals in organizational knowledge sharing. Information \& Management 45: 458-465.

Chuang C-H, Jackson SE and Jiang Y (2016) Can knowledge-intensive teamwork be managed? Examining the roles of HRM systems, leadership, and tacit knowledge. Journal of Management 42(2): 524-554.

Chung Y and Jackson SE (2013) The internal and external networks of knowledge-intensive teams: The role of task routineness. Journal of Management 39: 442-468.

Fullwood R, Rowley J and Delbridge R (2013) Knowledge sharing amongst academics in UK universities. Journal of Knowledge Management 17: 123-136.

Gonzalez-Brambila CN (2014) Social capital in academia. Scientometrics 101: 1609-1625.

Granovetter MS (1973) The strength of weak ties. American Journal of Sociology 78(6): $1360-1380$.

Grant RM (1996) Toward a knowledge based theory of the firm. Strategic Management Journal 17(S2): 109-122.

Han J, Han J and Brass DJ (2014) Human capital diversity in the creation of social capital for team creativity. Journal of Organizational Behavior 35: 54-71.

Hentonnen K, Johanson J-E and Janhonen M (2014) Work-team bonding and bridging social networks, team identity and performance effectiveness. Personnel Review 43(3): 330-349.

Holste JS and Fields D (2010) Trust and tacit knowledge sharing and use. Journal of Knowledge Management 14: 128-140.

$\mathrm{Hu} \mathrm{L}$ and Randel AE (2014) Knowledge sharing in teams: Social capital, extrinsic incentives, and team innovation. Group \& Organization Management 39(2): 213-243.

Inkpen AC and Tsang EWK (2005) Social capital, networks, and knowledge transfer. Academy of Management Review 30(1): 146-165.

Jacob M and Meek VL (2013) Scientific mobility and international research networks: Trends and policy tools for promoting research excellence and capacity building. Studies in Higher Education 38(3): 331-344.

Karahannan E and Preston DS (2013) The effect of social capital of the relationship between the CIO and top management team on firm performance. Journal of Management Information Systems 30(1): 15-56. 
Kim DH and Bak H-J (2016) How do scientists respond to performance-based incentives? Evidence from South Korea. International Public Management Journal 19(1): 31-52.

Levin DZ, Walter J, Appleyard MM, et al. (2016) Relational enhancement: How the relational dimension of social capital unlocks the value of network-bridging ties. Group \& Organization Management 41(4): 415-457.

Li EY, Liao CH and Yen HR (2013) Co-authorship networks and research impact: A social capital perspective. Research Policy 42: 1515-1530.

Liao J and Welsch H (2003) Social capital and entrepreneurial growth aspiration: A comparison of technology- and non-technology-based nascent entrepreneurs. The Journal of High Technology Management Research 14(1): 149-170.

Liu Y, Keller RT and Shih H-A (2011) The impact of team-member exchange, differentiation, team commitment, and knowledge sharing on R\&D project team performance. $R \& D$ Management 41: 274-287.

McAllister DJ (1995) Affect- and cognition-based trust as foundations for interpersonal cooperation in organizations. Academy of Management Journal 38: 24-59.

Maurer I, Bartsch V and Ebers M (2011) The value of intra-organizational social capital: How it fosters knowledge transfer, innovation performance, and growth. Organization Studies 32(2): 157-185.

Nahapiet J and Ghoshal S (1998) Social capital, intellectual capital and the organisational advantage. Academy of Management Review 23: 242-266.

Olmos-Peñuela J, Castro-Martínez E and D'Este P (2014) Knowledge transfer activities in social sciences and humanities: Explaining the interactions of research groups with nonacademic agents. Research Policy 43: 696-706.

Perianes-Rodríguez A, Olmeda-Gómez C and Moya-Anegón F (2010) Detecting, identifying and visualizing research groups in co-authorship networks. Scientometrics 82(2): 307-319.

Pezzoni M, Sterzi V and Lissoni F (2012) Career progress in centralized academic systems: Social capital and institutions in France and Italy. Research Policy 41(4): 704-719.

Phelps C, Heidl R and Wadhwa A (2012) Knowledge, networks, and knowledge networks: A review and research agenda. Journal of Management 38: 1115-1166.

Pil FK and Leana C (2009) Applying organizational research to public school reform: The effects of teacher human and social capital on student performance. Academy of Management Journal 52: 1101-1124.

Ramírez Y, Manzaneque M and Priego AM (2015) Formulating and elaborating a model for the measurement of intellectual capital in Spanish public universities. International Review of Administrative Sciences DOI: 10.1177/0020852315575168.

Ramos-Vielba I, Fernández-Esquinas M and Espinosa de los Monteros E (2010) Measuring university-industry collaboration in a regional innovation system. Scientometrics 84(3): 649-667.

Salaran M (2010) Research productivity and social capital in Australia higher education. Higher Education Quarterly 64(2): 133-148.

Stvilia B, Hinnant CC, Schindler K, et al. (2011) Composition of scientific teams and publication productivity at a national science lab. Journal of the American Society for Information, Science and Technology 62: 270-283.

Tangaraja G, Mohd Rasdi R, Abu Samah B, et al. (2016) Knowledge sharing is knowledge transfer: A misconception in the literature. Journal of Knowledge Management 20(4): 653-670. 
Tian J, Nakamori Y and Wierzbicki AP (2009) Knowledge management and knowledge creation in academia: A study based on surveys in a Japanese research university. Journal of Knowledge Management 13(2): 76-92.

Tsai W and Ghoshal S (1998) Social capital and value creation: The role of intrafirm networks. The Academy of Management Journal 41(4): 464-476.

Van den Hooff B and Huysman M (2009) Managing knowledge sharing: Emergent and engineering approaches. Information \& Management 46(1): 1-8.

Van Dijk A, Hendriks P and Romo-Leroux I (2016) Knowledge sharing and social capital in globally distributed execution. Journal of Knowledge Management 20(2): 327-343.

Wang J, Peter HP and Guan J (2006) Factors influencing knowledge productivity in German research groups: Lessons for developing countries. Journal of Knowledge Management 10: 113-126.

Wang S and Noe RA (2010) Knowledge sharing: A review and directions for future research. Human Resource Management Review 20(2): 115-131.

Wei-Li W and Yi-Chih L (2016) How to make a knowledge-sharing group: A group social capital perspective. Personnel Review 45(3): 523-538.

Widén-Wulff $G$ and Ginman M (2004) Explaining knowledge sharing in organizations through the dimensions of social capital. Journal of Information Science 30: 448-458.

Wong SS (2008) Task knowledge overlap and knowledge variety: The role of advice network structures and impact on group effectiveness. Journal of Organizational Behavior 29: 591-614.

Zboralski K (2009) Antecedents of knowledge sharing in communities of practice. Journal of Knowledge Management 13: 90-101.

Zheng W (2010) A social capital perspective of innovation from individuals to nations: Where is empirical literature directing us? International Journal of Management Reviews 12: 151-183.

Paola García-Sánchez is a PhD candidate at the University of Las Palmas de Gran Canaria, Spain. She is a member of the Managing Futures research group from the same university. Her research interest focuses on knowledge management and social capital, with a special emphasis on the study of that topic in the academic context.

Nieves L. Díaz-Díaz is Associate Professor of Finance at the University of Las Palmas de Gran Canaria, Spain. Her research interests concern knowledge management, innovation, corporate finance and ownership structure. She is the author of several articles in journals such as Research Policy, Management Decision, Industrial and Corporate Change and so on.

Petra De Saá-Pérez is Professor of Organizational Behaviour at the University of Las Palmas de Gran Canaria, Spain. She is interested in the study of human resources and knowledge management, and has several publications in The International Journal of Human Resource Management, Journal of Knowledge Management, $R \& D$ Management and so on. 


\section{Appendix I}

Table AI. Confirmatory factor analysis for sharing knowledge.

\begin{tabular}{|c|c|c|c|}
\hline Items & Com. & $\begin{array}{l}\text { Factor } \\
\text { load }\end{array}$ & $\begin{array}{l}\text { Cronbach's } \\
\text { alpha }\end{array}$ \\
\hline $\begin{array}{l}\text { Members of my research team share with } \\
\text { each other their research results (new } \\
\text { articles, projects, etc.) }\end{array}$ & 0.899 & 0.948 & 0.957 \\
\hline $\begin{array}{l}\text { Members of my research team always give } \\
\text { to other members their studies and } \\
\text { research knowledge }\end{array}$ & 0.893 & 0.945 & \\
\hline $\begin{array}{l}\text { Members of my research team share with } \\
\text { the rest their research experience }\end{array}$ & 0.855 & 0.924 & \\
\hline $\begin{array}{l}\text { Often, members of my research team } \\
\text { make suggestions to others about the } \\
\text { best investigation methods }\end{array}$ & 0.740 & 0.860 & \\
\hline $\begin{array}{l}\text { Members of my research team usually tell } \\
\text { each other if we do any research activity } \\
\text { that can facilitate the others' work }\end{array}$ & 0.696 & 0.834 & \\
\hline Eigenvalue & & 4.271 & \\
\hline Total \% explained variance & & 85.419 & \\
\hline Kaiser-Meyer-Olkin & & 0.898 & \\
\hline Barlett's test of sphericity: & & $1786.66^{* * * *}$ & \\
\hline
\end{tabular}

Note: Significant to: ${ }^{* * * *} p<0.01$.

Table A2. Confirmatory factor analysis for trust.

\begin{tabular}{lllc}
\hline Items & Com. & $\begin{array}{l}\text { Factor } \\
\text { load }\end{array}$ & $\begin{array}{c}\text { Cronbach's } \\
\text { alpha }\end{array}$ \\
\hline $\begin{array}{l}\text { Members of my research team always rely } \\
\text { on other members to offer their help } \\
\text { when necessary. }\end{array}$ & 0.959 & 0.979 & $0.96 \mathrm{I}$ \\
$\begin{array}{l}\text { Members of my research team will always } \\
\text { try to help each other if we have any }\end{array}$ & 0.865 & 0.930 & \\
$\quad$ problem. & & & \\
$\begin{array}{l}\text { Members of my research team can always } \\
\text { rely on others to make our job easier. }\end{array}$ & 0.859 & 0.927 & \\
$\begin{array}{l}\text { Eigenvalue } \\
\text { Total \% explained variance }\end{array}$ & & 2.787 & \\
Kaiser-Meyer-Olkin & & 92.912 & \\
Barlett's test of sphericity: & & 0.762 & \\
\hline
\end{tabular}

Note: Significant to: ${ }^{* * * *} p<0.01$. 